\title{
Calcium-Ion Incorporation into Titanium Surfaces Accompanied by Electrochemical Apatite-Deposition
}

\author{
Seiji BAN, Akira KAMIYA ${ }^{1}$ and Tsutomu SONODA ${ }^{1}$ \\ Department of Biomaterials Science, \\ Kagoshima University Dental School \\ 8-35-1, Sakuragaoka, Kagoshima 890-8544, Japan \\ ${ }^{1}$ Institute for Structural and Engineering Materials, \\ National Institute of Advanced Industrial Science and Technology \\ 2266-98 Anagahora, \\ Shimoshidami, Moriyama-ku, Nagoya 463-8560, Japan
}

Received July 5, 2002/Accepted September 30, 2002

\begin{abstract}
The depths of calcium-ion incorporation into a commercially pure titanium and an experimental $\beta$-type titanium alloy were determined using Auger electron spectroscopy. After the electrochemical deposition of apatite, new compositional gradients appeared in the profiles in which the $\mathrm{Ca}$ and $\mathrm{P}$ concentrations gradually decreased as a function of the depth up to 6-8 $\mathrm{nm}$. The relative concentration of $\mathrm{Ca}$ in the outermost layer was higher than that of $\mathrm{P}$. On the other hand, after the soaking in a simulated body fluid, the relative concentration of $\mathrm{P}$ was higher than that of $\mathrm{Ca}$ in the outermost layer. These results suggested that $\mathrm{Ca}$ ions were well incorporated into the outermost oxide layer of titanium accompanied by the electrochemical apatitedeposition on its surface.
\end{abstract}

Key words: Electrochemical deposition, Titanium, Auger electron spectroscopy

\section{INTRODUCTION}

Various coating methods of hydroxyapatite, $\mathrm{Ca}_{10}\left(\mathrm{PO}_{4}\right)_{6}(\mathrm{OH})_{2}$, have been studied as a bioactive surface treatment for metal implants. We reported that the electrochemical deposition of apatite can be used to easily create a homogeneous apatite coating on substrates having complicated shapes such as dental implants, and requires simple and small devices ${ }^{1,2)}$. Varying the electrochemical conditions can easily control the morphology of deposits. Both the size and the crystallinity of the needle-like apatite markedly increased with the electrolyte temperature ${ }^{3-7)}$. Furthermore, we reported that the electrochemical deposition of needle-like apatites on the surface of titanium significantly increased the bonding strength between bone and titanium in the early stages of implantation ${ }^{8-10)}$. Harada ${ }^{9)}$ reported that the electrochemically deposited apatite was completely converted to new bone at 9 weeks after implantation in rabbit femora. However, the bonding strength between bone and the titanium implant were maintained high. On the other hand, Hanawa et al. ${ }^{11}$ reported that calcium ions were incorporated into the titanium surface even immediately after soaking in the solutions containing calcium ions. Then, it can be assumed that calcium ions must be incorporated into the titanium surface after electrochemical deposition of apatite. 
The purpose of the present study was to evaluate the calcium-ion incorporation into titanium surfaces accompanied by the electrochemical deposition of apatite using Auger electron spectroscopy (AES).

\section{MATERIALS AND METHODS}

The electrolyte was heated in a stainless steel-autoclave assembled with two electrodes, a stirring screw, a pressure gauge, a pressure valve, a thermo-couple and an electric heater. A platinum plate, $20 \times 20 \times 0.5 \mathrm{~mm}$, was used as the counter electrode. A commercially pure titanium (cpTi) plate (KS-50, Kobelco, Kobe, Japan) and an experimental Ti53.4-Nb29-Ta13-Zr4.6 (TNTZ) alloy ${ }^{12)}$ plate, $20 \times 20 \times 0.5 \mathrm{~mm}$, were employed as the working electrodes. These metal plates were ground using 600 grit to 1200 -grit abrasive papers and polished with $1 \mu \mathrm{m}$ and $0.3 \mu \mathrm{m} \mathrm{Al}_{2} \mathrm{O}_{3}$ powder on a metallographic polishing wheel. The electrolyte was prepared by dissolving given amounts of reagent-grade chemicals of $137.8 \mathrm{mM}$ of $\mathrm{NaCl}, 1.67 \mathrm{mM}$ of $\mathrm{K}_{2} \mathrm{HPO}_{4}$, and $2.5 \mathrm{mM}$ of $\mathrm{CaCl}_{2} \cdot 2 \mathrm{H}_{2} \mathrm{O}$ into distilled water. The solution was buffered to $\mathrm{pH} 7.2$ with $50 \mathrm{mM}$ tris(hydroxymethyl)aminomethane $\left[\left(\mathrm{CH}_{2} \mathrm{OH}\right)_{3} \mathrm{CNH}_{2}\right]$ and an adequate amount of hydrochloric acid. The electrolyte was heated at $100^{\circ} \mathrm{C}$ using an electric heater and agitated by a stainless steal screw. The current was maintained at 12.5 $\mathrm{mA} / \mathrm{cm}^{2}$ by a DC power supply for $1 \mathrm{hr}$. After loading of the constant current, the titanium plates loaded as cathodes were rinsed with distilled water and dried at 37 ${ }^{\circ} \mathrm{C}$ in air. The deposited apatite was mechanically removed by adhesive tape and polishing cloth, and finally cleaned in acetone using an ultrasonic cleaning bath.

The surface of the specimen was characterized by AES (JAMP-10SX, JEOL, Tokyo, Japan). AES spectra in the range between 0 to $1,000 \mathrm{eV}$ were measured for $1 \times 1 \mathrm{~mm}$ areas. The concentrations of calcium, phosphorus, oxygen, titanium, and niobium were determined in depth by argon ion etching for $30 \mathrm{~s}$ at an acceleration voltage of $3 \mathrm{kV}$ and an emission current of $30 \mathrm{~mA}$. The etching rate was calibrated as $12.5 \mathrm{~nm} / \mathrm{min}$ using $\mathrm{Si} / \mathrm{SiO}_{2}$ in which the $100 \mathrm{~nm}$ thick layer was removed by 16 etchings. According to a previous study ${ }^{13)}$, this sputtering rate was converted to the rate for titanium oxide, $6.25 \mathrm{~nm} / \mathrm{min}$. The metal plates as polished and after soaking in a simulated body fluid $(\mathrm{SBF})^{14)}$ for $24 \mathrm{hr}$ at $37^{\circ} \mathrm{C}$ were also characterized to compare with the results of the specimen with electrochemical apatite coating.

\section{RESULTS}

Figs. 1, 2, and 3 show the AES depth profiles of cpTi without any treatment, after soaking in SBF for $24 \mathrm{hr}$, and after the electrochemical deposition of apatite at 100 ${ }^{\circ} \mathrm{C}$. Judging from the changes in the relative concentration of $\mathrm{Ti}$ and $\mathrm{O}$ in the depth profiles of cpTi without any treatments (Fig. 1), the surface of untreated cpTi appears to be covered with a passive layer of titanium oxide about $15 \mathrm{~nm}$ thick, and this thickness was similar to those of cpTi after soaking in SBF (Fig. 2) and after the electrochemical deposition of apatite (Fig. 3). There were no marked changes in 


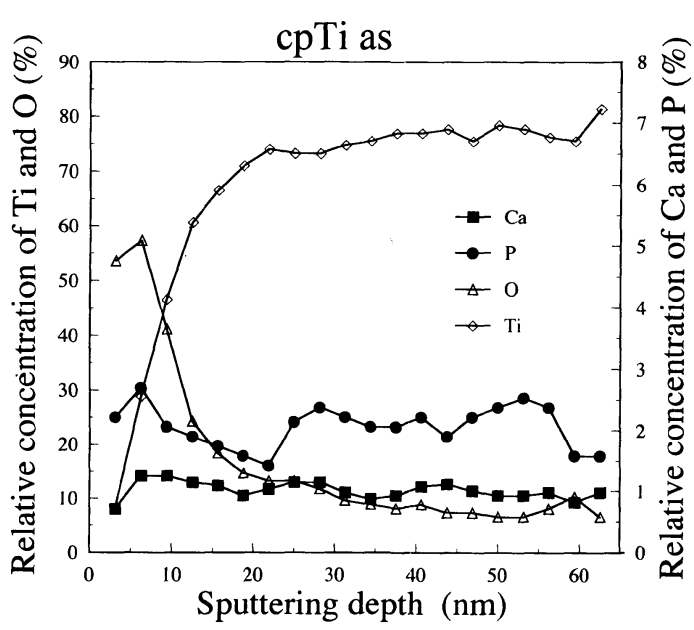

Fig. 1 AES depth profiles of the cpTi surface without any treatment.

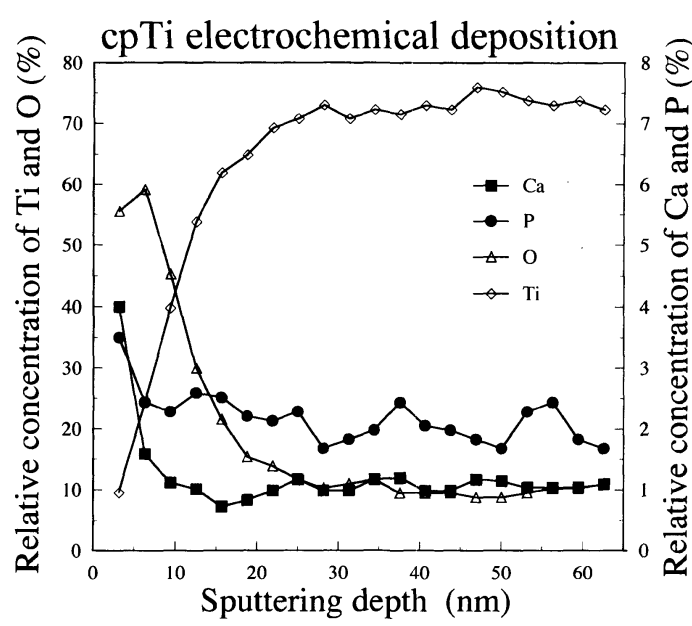

Fig. 3 AES depth profiles of the cpTi surface after the electrochemical deposition of apatite at $100^{\circ} \mathrm{C}$ and cleaning.

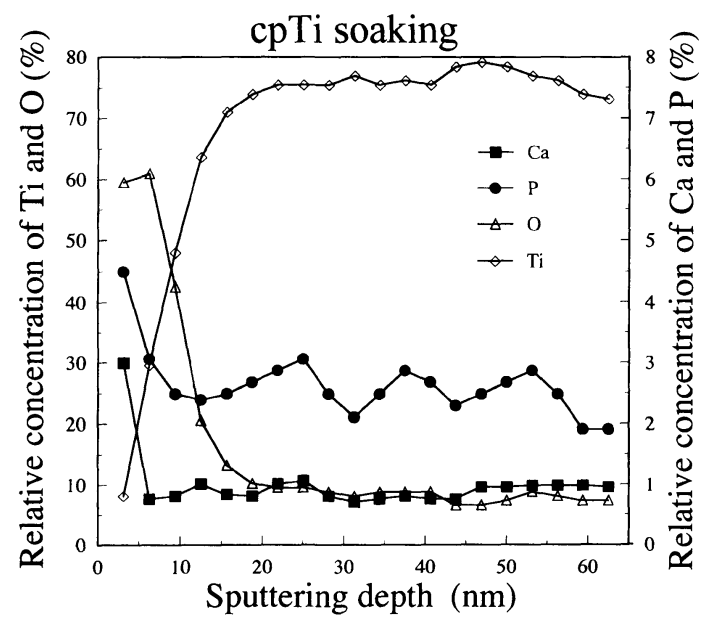

Fig. 2 AES depth profiles of the cp'Ti surface after soaking in SBF for $24 \mathrm{hr}$.

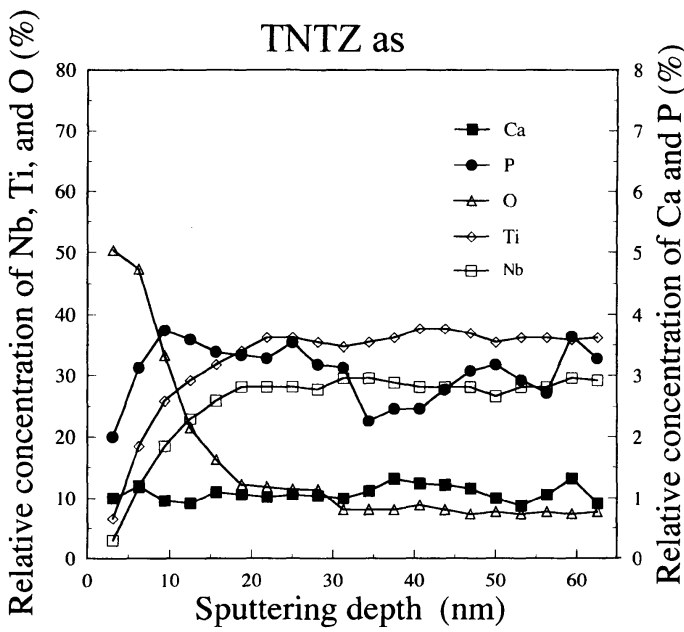

Fig. 4 AES depth profiles of the TNTZ alloy surface without any treatments.

the relative concentrations of $\mathrm{Ca}$ and $\mathrm{P}$ for the untreated cpTi as a function of depth. After the electrochemical deposition of apatite (Fig. 3), new compositional gradients appeared in the profiles in which $\mathrm{Ca}$ and $\mathrm{P}$ concentrations gradually decreased as a function of the depth up to $6-8 \mathrm{~nm}$ and the relative concentration of $\mathrm{Ca}$ in the outermost layer was higher than that of $\mathrm{P}$. On the other hand, after soaking in SBF (Fig. 2), the relative concentration of $\mathrm{P}$ was higher than that of $\mathrm{Ca}$ in the outermost layer. Although $\mathrm{K}$ and $\mathrm{Na}$ ions were also contained in these solutions, neither of these cations were detected in the surface layer. 


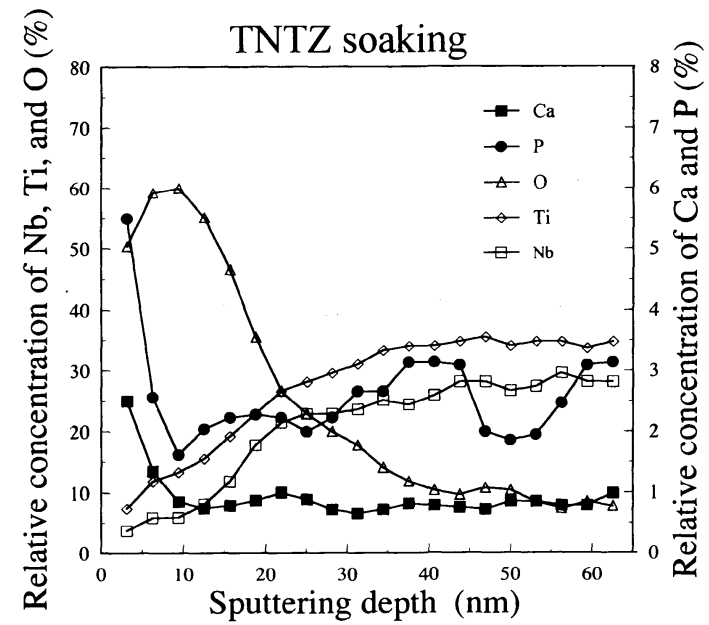

Fig. 5 AES depth profiles of the TNTZ alloy surface after soaking in SBF for 24 hr.

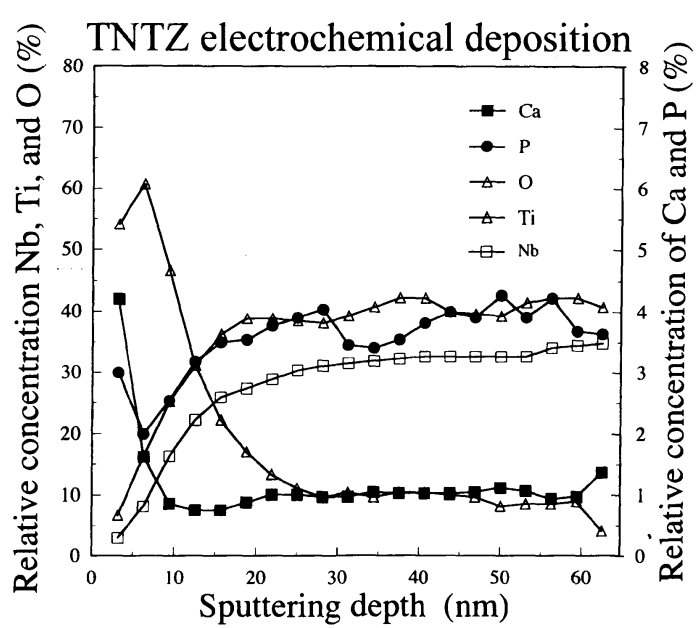

Fig. 6 AES depth profiles of the TNTZ alloy surface after the electrochemical deposition of apatite at $100^{\circ} \mathrm{C}$ and cleaning.

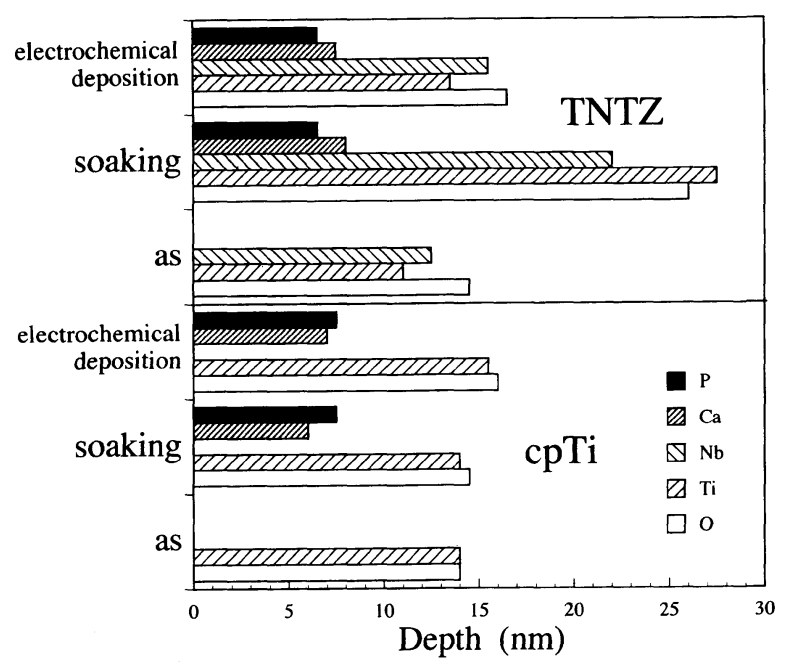

Fig. 7 Critical depth of the relative concentration of $\mathrm{Ca}, \mathrm{P}, \mathrm{Ti}, \mathrm{Nb}$, and $\mathrm{O}$ in the AES profiles shown Figs. 1-6.

Figs. 4, 5, and 6 show the AES depth profiles of the TNTZ alloy without any treatment, after soaking in SBF for $24 \mathrm{hr}$, and after the electrochemical deposition of apatite at $100^{\circ} \mathrm{C}$, respectively. TNTZ alloy showed similar results with those of $\mathrm{cpTi}$, except for the thickness of the passive layer of TNTZ after soaking in SBF (Fig. 5). After the electrochemical deposition of apatite (Fig.6), the Ca and P concentrations 
gradually decreased as a function of the depth up to 6-8 $\mathrm{nm}$ and the relative concentration of $\mathrm{Ca}$ in the outermost layer was higher than that of $\mathrm{P}$. After soaking in $\mathrm{SBF}$ (Fig.5), the relative concentration of $\mathrm{P}$ was higher than that of $\mathrm{Ca}$ in the outermost layer. Although alloying species of $\mathrm{Ta}$ and $\mathrm{Zr}$ were not detected, the $\mathrm{Nb}$ concentration increased to a depth similar to the gradation of Ti.

Fig. 7 shows the depth of the critical change in the relative concentration profiles of elements. The critical depths were determined with extrapolation in each AES depth profile shown in Figs. 1 to 6 . It is suggested that the depths of the critical concentration change of $\mathrm{Ti}$ and $\mathrm{O}$ are the thickness of the passive layer and the critical depth of $\mathrm{Ca}$ is the penetration depth of $\mathrm{Ca}$ in the passive layer. Nevertheless, with and without treatment, the thickness of the passive layer of cpTi and TNTZ were about $15 \mathrm{~nm}$, except TNTZ after soaking in SBF had a thicker layer about 25 $\mathrm{nm}$.

\section{DISCUSSION}

The ion concentrations of the surface of titanium with various bioactive treatments have been characterized using X-ray photo-electron spectroscopy (XPS $)^{11,13,15-19)}$ and $\mathrm{AES}^{12,20-23)}$. XPS is suitable to analyze the chemical state of elements in thin layers on the surface and AES can obtain depth profiles in ultra-thin layers on the surface using argon sputtering, because XPS uses photoelectrons excited by X-rays and AES is based on Auger electrons excited by electron beams. In the present study, AES was employed to obtain depth information of calcium ion incorporation on the titanium surface accompanied with the electrochemical apatite deposition.

The thicknesses of the passive layer of titanium varied with the methods of the surface finish and their conditions. Hanawa et $a l .{ }^{11)}$ reported that final polishing with No.1200 SiC paper had a surface film of $4 \mathrm{~nm}$. Kim et al. ${ }^{22)}$ reported that cpTi abraded with No.400 diamond plates was covered with a titanium oxide layer about $20 \mathrm{~nm}$ thick. Larsson et $a ._{.}{ }^{24)}$ reported that machined or electropolished titanium had thin oxides, less than $5 \mathrm{~nm}$, and anodized titanium had thick oxides of $180-200 \mathrm{~nm}$. It appears that the large thickness of the passive layer of TNTZ after soaking in SBF depended on the formation of $\mathrm{Nb}_{2} \mathrm{O}_{5}$. Although $\mathrm{Nb}_{2} \mathrm{O}_{5}$ was not detected by the X-ray diffraction study, it is possible that the passive oxide layer of TNTZ was a solid solution of $\mathrm{TiO}_{2}-\mathrm{Nb}_{2} \mathrm{O}_{5}$, considering previous results ${ }^{25,26)}$. In our previous study ${ }^{25)}$, the oxides on the surface of TNTZ at high temperatures $\left(1,150^{\circ} \mathrm{C}\right.$ and $\left.1,400^{\circ} \mathrm{C}\right)$ were identified as $\mathrm{Nb}_{2} \mathrm{O}_{5}, \mathrm{Zr}_{0.25} \mathrm{Ti}_{0.75} \mathrm{Nb}_{2} \mathrm{O}_{7}$, and $\mathrm{TiO}_{2}$. It is suggested that the constituents of the alloys reacted with the oxide investments and atmospheric oxygen to form the external oxides due to the free energy of oxide formation and the concentration of each element on the metal surface. In the present study, the alloy was kept at relatively low temperatures (room temperature, $37^{\circ} \mathrm{C}$, and $100^{\circ} \mathrm{C}$ ). If the oxide that formed at these temperatures also depends on similar factors, it can be well explained that $\mathrm{Nb}$ was detected in relatively high concentrations in the surface oxide passive layer, because $\mathrm{Nb}$ existed in the solid solution of $\mathrm{TiO}_{2}$ and $\mathrm{Nb}_{2} \mathrm{O}_{5}$. Furthermore, it is known 
that $\mathrm{Nb}_{2} \mathrm{O}_{5}$ tends to be a flaky shape with apparently large volumes ${ }^{27)}$. During the electrochemical deposition of apatite, TNTZ was kept at the same cathodic potential as the electropolishing procedure. In the cathodic reaction, the oxide of the cathode is partially deoxidized due to the production of hydrogen gas, namely the reducing process. Therefore, the growth of the oxide layer of the electrode was inhibited during the electrochemical deposition of apatite.

The penetration depths of Ca also varied with the treatment methods and conditions. Krupa et $a l^{28)}$ reported that the maximum concentration of $\mathrm{Ca}$ with Ca-ion implantation $\left(10^{17} \mathrm{Ca}^{2+} / \mathrm{cm}^{2}\right)$ using ion beams occurred at a depth of about $4 \mathrm{~nm}$ and Ca partially penetrated into metallic titanium at about 40-50 nm deep. Ong and Lucas $^{21)}$ reported that the oxides on autoclaved titanium surfaces increased from 4.5 $\mathrm{nm}$ to $6.9 \mathrm{~nm}$ after 1 week immersion in a phosphate-buffered solution. Hanawa et al. reported that, after immersion in Ca-containing solution, the surface was modified to form calcium-hydroxide and/or calcium titanate ${ }^{16)}$ and the thickness of this modified layer was only 2-3 $\mathrm{nm}^{11)}$. As mentioned above, it is rare that an oxide layer is newly formed on the cathode during the electrochemical deposition of apatite. However, cations such as $\mathrm{Ca}^{2+}$ can diffuse into the oxide layer due to the coulomb potential and form calcium-titanate. As described above, $\mathrm{K}$ and $\mathrm{Na}$ ions were not detected in the surface layer of titanium and its alloy. Although $\mathrm{K}^{+}$and $\mathrm{Na}^{+}$in the electrolyte also diffused into the oxide layer, it is possible that these cations are released from the oxide layer during soaking in a solution. Since the bonding energies of $\mathrm{K}$ and $\mathrm{Na}$ to oxygen are smaller than that of calcium, these oxides are more soluble than calcium oxide.

These results suggested that $\mathrm{Ca}$ ions were well incorporated into the outermost oxide layer of titanium accompanied by the electrochemical deposition of apatite on its surface. Therefore, it can be expected that the oxide layer containing calcium acts as the bonding layer bonding between titanium and bone after the loss of electrochemically deposited apatite due to biological resorption.

\section{ACKNOWLEDGEMENT}

This work was supported in part by a Grant-in-Aid for General Scientific Research and a Science Frontier Promotion Program from the Ministry of Education, Culture, Sports, Science, and Technology of Japan.

\section{REFERENCES}

1) Ban, S. and Maruno, S.: Electrochemical synthesis of calcium phosphates in a simulated body fluid, Bioceramics Vol.5, Yamamuro, T. et al. (eds.), Kobunshi Kankokai, Kyoto, 1992, pp.49-56.

2) Ban, S. and Maruno, S.: Deposition of calcium phosphate on titanium by electrochemical process in simulated body fluid, Jpn $J$ Appl Phys 32(10B) : L1577-1580, 1993.

3) Ban, S. and Maruno, S.: Effect of temperature on electrochemical deposition of calcium phosphate coatings in a simulated body fluid, Biomaterials 16(13): 977-981, 1995.

4) Ban, S., Maruno, S., Harada, A., Hattori, M., Narita, K. and Hasegawa, J.: Effect of 
temperature on morphology of calcium phosphates deposited by electrochemical method, Dent Mater J 15(1) : 31-38, 1996.

5) Ban, S. and Maruno, S.: Morphology and microstructure of electrochemically deposited calcium phosphates in a modified simulated body fluid, Biomaterials 19(14): 1245-1253, 1998.

6) Ban, S. and Maruno, S.: Hydrothermal-electrochemical deposition of hydroxyapatite, $J$ Biomed Mater Res 42(3): 387-395, 1998.

7) Ban, S., Matsuo, K., Mizutani, N. and Hasegawa, J.: Hydrothermal-electrochemical deposition of calcium phosphates on various metals, Dent Mater $J$ 18(3) : 259-270, 1999.

8) Ban, S., Maruno, S., Arimoto, N., Harada, A. and Hasegawa, J.: Effect of electrochemically deposited apatite coating on bonding of bone to the HA-G-Ti composite and titanium, $J$ Biomed Mat Res 36(1): 9-15, 1997.

9) Harada, A.: Bioactive surface modification of metal implants by electrochemical apatite coating, Aichi-Gakuin. Dent Sci 35(1): 93-107, 1997. (in Japanese)

10) Ban, S., Arimoto, N., Harada, A., Hasegawa, J. and Maruno, S.: Bioactivity of hydrothermal-electrochemically deposited apatite in vitro and in vivo, Bioceramics Vol.13, Giannini, S. and Moroni, A. (eds.), Trans Tech Publications, Switzerland, 2000, pp.159-162.

11) Hanawa, T. and Ota, M.: Calcium phosphate naturally formed on titanium in electrolyte solution, Biomaterials 12(8): 767-774, 1991.

12) Niinomi, M.: Development of $\beta$-type titanium alloys for implant materials, Materia Japan 37(19) : 843-846, 1998. (in Japanese)

13) Sawase, T., Hai, K., Yoshida, K., Baba, K., Hatada, R. and Atsuta, M.: Spectroscopic studies of three osseointegrated implants, J Dent 26(2): 119-124, 1998.

14) Kokubo, T., Hayashi, T., Sakka, S., Kitsugi, T. and Yamamuro, T.: Bonding between bioactive glasses, glass-ceramics or ceramics in a simulated body fluid. Yogyo-KyokaiShi 95(8) : 785-791, 1987.

15) Hanawa, T., Ukai, H. and Murakami, K.: X-ray photoelectron spectroscopy of calciumion-implanted titanium, $J$ Electron Spectrosc 63(4) : 347-354, 1993.

16) Hanawa, T., Kon, M., Ukai, H., Murakami, K., Miyamoto Y. and Asaoka, K.: Surface modifications of titanium in calcium-ion-containing solutions, $J$ Biomed Mater Res 34 (3) : 274-278, 1997.

17) Ohtsuki, C., Iida, H., Hayakawa, S. and Osaka, A.: Bioactivity of titanium treated with hydrogen peroxide solutions containing metal chlorides, $J$ Biomed Mater Res 35(1) : 3947, 1997.

18) Milella, E., Cosentino, F., Licciulli, A. and Massaro, C.: Preparation and characterization of titania/hydroxyapatite composite coatings obtained by sol-gel process, Biomaterials 22(11) : 1425-1431, 2001.

19) Yoshinari, M., Oda, Y., Ueki, H. and Yokose, S.: Immobilization of bisphosphonates on surface modified titanium, Biomaterials 22(7):709-715, 2001.

20) Li, X., Weng, J., Tong, W., Zuo, C., Zhang, X., Wang, P. and Liu, Z.: Characterization of hydroxyapatite film mixed interface by $\mathrm{Ar}^{+}$ion beam enhanced deposition, Biomaterials 18(22) : 1487-93, 1997.

21) Ong, J. L. and Lucas, L. C.: Auger electron spectroscopy and its use for the characterization of titanium and hydroxyapatite surfaces, Biomaterials 19(4-5): 455-464, 1998.

22) Kim, H.-M., Miyaji, F., Kokubo, T., Nishiguchi, S. and Nakamura, T.: Graded surface structure of bioactive titanium prepared by chemical treatment, $J$ Biomed Mater Res, 45 (1) : 100-107, 1999.

23) Sul, Y. T., Johansson, C. B., Jeong, Y. and Albrektsson, T.: The electrochemical oxide growth behaviour on titanium in acid and alkaline electrolytes, Med Eng Phys 23(5): 329-346, 2001.

24) Larsson, C., Emanuelsson, L., Thomsen, P., Ericson, L. E., Aronsson, B.-O., Kasemo, B. and Lausmaa, J.: Bone response to surface modified titanium implants - studies on 
the tissue response after 1 year to machined and electropolished implants with different oxide thickness, J Mater Sci Mat Med 8(12): 721-729, 1997.

25) Ban, S., Watanabe, T., Mizutani, N., Fukui, H., Hasegawa, J. and Nakamura, H.: Interfacial oxidations of pure titanium and titanium alloys with investments, Dent Mater $J 19$ (4) : 352-362, 2000.

26) Chen, Y.S. and Rosa, C. J.: High temperature oxidation of Ti-43.2wt\% Nb alloy, Oxidation of Metals 14(2): 147-165, 1980.

27) Tsuruta, S., Ban, S., Hasegawa, J., Hayashi, S., Iijima, K. and Yamamura, Y.: Application of gypsum-bonded investment containing niobium carbide on casting of alloy for metal-ceramic restoration, $J$ J Dent Mater 9(4):617-622, 1990. (in Japanese)

28) Krupa, D., Baszkiewicz, J., Kozubowski, J. A., Barcz, A., Sobczak, J. W., Bilinski, A., Lewandowska-Szumiel, M. and Rajchel, B.: Effect of calcium-ion implantation on the corrosion resistance and biocompatibility of titanium, Biomaterials 22(15):2139-2151, 2001 . 